\title{
Norbert Berthold
}

\section{Multinationale Unternehmen und nationale Währungspolitik}

Eine Analyse des Interessenkonflikts zwischen kurzfristigem Finanzmanagement multinationaler Unternehmen und nationaler Währungspolitik.

Schriftenreihe des Instituts für Allgemeine Wirtschaftsforschung der Albert-LudwigsUniversität Freiburg, Bd. 8, Rudolf Haufe Verlag, Freiburg, 1981, 208 Seiten, DM 59,-

Die Analyse der finanzpolitischen Verhaltensweisen von (vor allem deutschen und USamerikanischen) multinationalen Unternehmen (MNU) zeigt sehr eindringlich, welche mannigfaltigen Möglichkeiten solche Konzerne haben, die nationalstaatlichen Versuche zur Regulierung von Wirtschafts- und Währungsverhältnissen zu konterkarieren. Dabei beschränkt sich der Autor nicht auf theoretische (modellplatonische) Reflexionen, sondern untermauert seine Thesen durch empirische Befunde aus der relevanten Sekundärliteratur. Z. B. werden die bisher bekannt gewordenen Praktiken der MNU bei der Manipulation konzerninterner Verrechnungspreise - die bis zu $300 \%$ von den sonst üblichen Marktpreisen abweichen können, und zwar nicht nur in Entwicklungsländern - aufgelistet und umsichtig interpretiert.

Ferner werden die vielfältigen Reaktionen der MNU auf die Einführung von staatlichen Kapitalverkehrskontrollen, von gespaltenen Wechselkursen und von Währungsauf- und -abwertungen - sowohl theoretisch wie auch empirisch - dargestellt. Sehr differenziert wird das Verhalten der Konzerne während der drei Währungskrisen in der Bundesrepublik und in Großbritannien zwischen 1971 und 1973 analysiert: tatsächlich haben sie die spekulationsbedingten finanziellen Aktivitäten erheblich (zwischen 15 und $30 \%$ aller Kapitalzuflüsse) bestimmt. Allerdings - fügt der Autor tröstend hinzu - hätten sie von ihren Möglichkeiten, kurzfristig mobilisierbare liquide Mittel (30 Mrd. DM im Falle der BRD) als Störpotential einzusetzen, nur suboptimal Gebrauch gemacht. Jedenfalls stünde außerfrage, daß trotz gewisser erfolgreichen Auswirkungen administrativer Beschränkungen der nationalen Währungsbehörden die finanziellen Aktivitäten der Unternehmen "einen stark störenden Einfluß auf die nationale Geldversorgung ausüben" (Resümé der Studie).

Es handle sich um eine sorgfältig recherchierte, klar strukturierte und auch verständlich geschriebene Untersuchung. Leider wird zu wenig zwischen den Währungsproblemen und -politiken von Industrie- und Entwicklungsländern unterschieden; hingegen werden immer wieder die unterschiedlichen Handlungsspielräume von multinationalen Konzernen im Gegensatz zu nationalen Unternehmen betont. Insgesamt also eine willkommene Bereicherung der seriösen Literatur über ein heikles Thema, über das jetzt mehr Klarheit herrschen dürfte als vorher.

Rainer Tetzlaff 